Article

\title{
Antifungal Properties of Pure Silver Films with Nanoparticles Induced by Pulsed-Laser Dewetting Process
}

\author{
Ying-Hong Lin ${ }^{1}{ }^{1}$, Jyun-Jhih Wang ${ }^{2}$, Yung-Ting Wang ${ }^{2}$, Hsuan-Kai Lin ${ }^{2, *}$ and Yi-Jia Lin ${ }^{1}$ \\ 1 Department of Plant Medicine, National Pingtung University of Science and Technology, Pingtung 912, \\ Taiwan; pmyhlin@mail.npust.edu.tw (Y.-H.L.); pipig321@outlook.com (Y.-J.L.) \\ 2 Graduate Institute of Materials Engineering, National Pingtung University of Science and Technology, \\ Pingtung 912, Taiwan; a3311a33@gmail.com (J.-J.W.); tim90842002@gmail.com (Y.-T.W.) \\ * Correspondence: HKLin@mail.npust.edu.tw
}

Received: 19 February 2020; Accepted: 21 March 2020; Published: 26 March 2020

\begin{abstract}
Silver particles were prepared by dewetting Ag films coated on glass using a fiber laser. The size of the particles was controlled in the range of $92 \mathrm{~nm}-1.2 \mu \mathrm{m}$ by adjusting the thickness of the Ag film. The structural properties and surface roughness of the particles were evaluated by means of scanning electron microscopy. In addition, the antifungal activity of the Ag particles was examined using spore suspensions of Colletotrichum gloeosporioides. It is shown that particles with a size of $1.2 \mu \mathrm{m}$ achieved $100 \%$ inhibition of conidia growth of $C$. gloeosporioides after a contact time of just $5 \mathrm{~min}$. Furthermore, the smaller particles also achieved good antifungal activity given a longer contact time. Similar results were observed for spore germination and pathogenicity tests performed on mango fruit and leaves. Overall, the results confirm that Ag particles have an excellent antifungal effect on C. gloeosporioides.
\end{abstract}

Keywords: Ag; colletotrichum gloeosporioides; laser; dewetting

\section{Introduction}

Mango (Mangifera indica L.) is a popular fruit with a strong and distinctive flavor that is widely grown in many tropical and subtropical countries [1]. However, during the growth stage, the mango fruit and leaves are often affected by anthracnose disease, in which Colletotrichum gloeosporioides fungi cause severe lesions with black spots. Some estimates have placed the incidence of anthracnose disease in farmers' fields as high as $36 \%-74 \%$ [2]. Traditionally, C. gloeosporioides fungi are treated by chemical spraying. However, the fungi have gradually developed resistance to commercial fungicides, and hence alternative methods for combating anthracnose disease are required [3].

Metallic antimicrobial surfaces are widely used for the storage and delivery of water. For example, studies have shown that Ag bottles and vessels provide an effective means of preventing the spoilage of stored water by bacteria [4]. Furthermore, surface chemistry modifications of such surfaces-combined with proper cleaning products and procedures-produces a further improvement in antimicrobial performance [5]. In recent years, the antifungal activity of nanoparticles (NPs) against some phytopathogenic fungi has been investigated [6]. Many studies have demonstrated the effectiveness of $\mathrm{Ag}$, $\mathrm{Cu}$ and $\mathrm{ZnO}$ nanoparticles (NPs) in inhibiting the activity of phytopathogenic fungi [3,7-9]. Ag NPs show a particularly strong bactericidal performance: with silver additions, the textile has antimicrobial activities, while thin films coated on the substrate have an antifungal function. Chowdappa [10] reported that chitosan-AgNP composite exhibits a higher antifungal activity against $C$. gloeosporioides than its components [11]. The biological activity of metallic glass materials has 
also attracted significant attention in recent years [12,13]. Chen [14] reported that the growth area of microbes on Zr-based metallic glass films was smaller than that on SUS304 substrates. Furthermore, the coatings exhibited a particularly long-term antimicrobial effect for Pseudomonas aeruginosa. The thin film metallic glasses extended the attainable size of the metallic glass and showed a potential application in the medical field.

Nowadays, most applications on plant pathogens use nanomaterials as fungicides [15]. Studies have shown that $\mathrm{Cu}$ nanoparticles inhibit plant pathogens such as Phoma destructiva, Curvularia lunata and Alternaria, while Ag particles suppress the growth of Macrophomina phaseolina and Rhizoctonia solani [7]. Therefore, nanoparticles have potential for development as a bacteriostatic or fungicide. Various techniques are available for the production of micro- and nanoscale metallic particles, including mechanochemical methods [16], green synthesis [17], spray pyrolysis [18], sol-gel [19], chemical vapor deposition [20] and dewetting [21]. In the latter method, a metallic film is deposited on a glass substrate then annealed, resulting in a dewetting phenomenon that minimizes the total energy of the free surfaces of the film and substrate. Compared to other methods, dewetting has the advantages of large area coverage, low cost and production of ordered NPs. Furthermore, the rapid thermal treatment of thin $\mathrm{Ag} / \mathrm{Cu}$ bilayers also enables the production of composite $\mathrm{Ag}$-Cu nanoparticles [22]. However, the high melting temperatures of most metals are not easily achievable using conventional heating methods. Therefore, the dewetting process is generally performed using high-energy sources such as focused ion beams and lasers [23].

The feasibility of pulsed laser-induced dewetting, especially using nanosecond pulses, has attracted significant attention in the literature [24-30]. However, only scant information is available regarding the synthesis of metallic NPs using a high repetition rate laser. Accordingly, the present study prepares Ag particles with various sizes using a high repetition rate pulsed laser and an Ag film with a carefully controlled thickness. The antifungal activity of the Ag particles is investigated by examining the conidia growth and germination rate of $C$. gloeosporioides spores in both in vitro experiments and in vivo experiments performed using mango fruit and leaves.

\section{Experiment}

\subsection{Silver Particle Preparation}

Glass substrates (AGC G2, $150 \times 150 \times 0.7 \mathrm{~mm}$ ) were cleaned ultrasonically in deionized water for $15 \mathrm{~min}$. The substrates were dried with hot air then transferred to an SSI-T500-1 thermal evaporator system. The base pressure of the evaporation chamber was set as $6 \times 10^{-6}$ Torr prior to the thermal evaporation process. Silver pellets (Ultimate Materilas Technology Co., Taiwan) were loaded into a tungsten boat in the evaporation chamber and vaporized by a resistive heat source. The growth conditions of the Ag film on the glass substrate were controlled by adjusting the current $\left(\mathrm{I}_{\mathrm{Ag}}\right)$ and time of the evaporation process. In particular, $\mathrm{I}_{\mathrm{Ag}}$ was fixed at $60 \mathrm{~A}$ and the time was adjusted as required to produce Ag thin films with thicknesses of 10 and $50 \mathrm{~nm}$, respectively. The as-deposited films were dewetted using a fiber laser (SPI-12, UK, wavelength $1064 \mathrm{~nm}$ ) with repetition rates ranging from $50-500 \mathrm{kHz}$ and irradiation powers in the range of 2-12.5 W. For all of the samples, the laser spot size and pulse duration were set as $40 \mu \mathrm{m}$ and $30 \mathrm{~ns}$, respectively. Moreover, the laser scanning speed was varied in the range of $25-1200 \mathrm{~mm} / \mathrm{s}$. The pulse energy (E) was computed as [31]

$$
\mathrm{E}=\mathrm{P}_{\mathrm{AVG}} / \text { rep, }
$$

where $\mathrm{P}_{\mathrm{AVG}}$ is the average power of the pulse laser and rep is the laser repetition rate. From Equation (1), it can be seen that the pulse energy reduces as the repetition rate increases. For the irradiation powers and repetition rates considered in the present study, the pulse energy varied from 5 to $250 \mu \mathrm{J}$. In this study, the fluence was from 1 to $19 \mathrm{~J} / \mathrm{cm}^{2}$. The shape, size and cross-sectional height of the Ag particles produced in the laser dewetting process were observed by an optical microscope (OM, HRM-300, Korea) and a scanning electron microscope (SEM, JSM-7600F, Tokyo, Japan). The wettability of the different 
samples was evaluated using a contact angle measurement system (OCA 15EC, Dataphysics, Germany). Finally, the surface roughness was measured using a surface roughness analyzer (Alpha-Step, KLA D-300, CA, USA) based on five separate measurements obtained under a load of $80 \mathrm{mg}$ each time.

\subsection{Antifungal Test}

Pathogenic C. gloeosporioides isolate (NCBI accession number KP900284.1) was cultured in potato dextrose broth (PDB) at $28^{\circ} \mathrm{C}$ for 7 days. After incubation, C. gloeosporioides spores were harvested by centrifugation (Heraeus Pico 17 Microcentrifuge, Thermo Scientific, Massachusetts, USA) at 13,000 rpm for $5 \mathrm{~min}$ and re-suspended in $\mathrm{ddH}_{2} \mathrm{O}$. Next, $2-\mu \mathrm{L}$ drops of the spore suspension were placed on a slide and the number of spore colonies was counted under a microscope. To assess the antifungal activity of the Ag particles, $150-\mu \mathrm{L}$ spore suspensions of $C$. gloeosporioides were transferred with a micropipette to contact with the particles for 1, 5, 10 and $15 \mathrm{~min}$, respectively. The spore suspensions were then transferred to potato dextrose agar (PDA) medium to evaluate the colony-forming units (CFUs) after $48 \mathrm{~h}$ incubation at $28^{\circ} \mathrm{C}$. The antifungal efficacy (AE) of each sample was evaluated as [1- (A - B)] $\times 100$, where $\mathrm{A}$ is the number of CFUs following contact with the Ag particles and $\mathrm{B}$ is the number of CFUs following contact with an uncoated glass slide (control).

\subsection{Spore germination Inhibition Assay}

The possible antifungal mechanism of the NPs was investigated by means of spore germination inhibition assays. Aliquots of C. gloeosporioides spore suspension were contacted with Ag NPs for 1 and $15 \mathrm{~min}$, respectively, and $20-\mu \mathrm{L}$ spore suspensions from each condition were transferred to glass slides that were then incubated at $25^{\circ} \mathrm{C}$. After $4,8,12,24$ and $48 \mathrm{~h}$ incubation, the spore germination was observed under a microscope and the percentage of spore germination was calculated. The spore germination rate $(\%)$ was calculated as $[\mathrm{A} / \mathrm{B}] \times 100$, where $\mathrm{A}$ is the number of $\mathrm{CFU}$ s for the Ag sample and $B$ is the number of CFUs for the control sample.

\subsection{Morphology Analysis}

Disks of $C$. gloeosporioides $(1 \mathrm{~cm})$ and spores treated with $\mathrm{Ag}$ particles and glass were cultured in PDA medium and distilled water, respectively, in darkness at $28{ }^{\circ} \mathrm{C}$ for every day. The colony count, hyphal morphology and mycelial radial growth rate were examined every day. In addition, the appressorium formation of each sample was observed at $0,2,4,6$ and $8 \mathrm{~h}$ after inoculation.

\subsection{Virulence Assay}

Semi-ripe fruits of the mango cultivar 'Irwin' were prepared with weights of approximately $300 \mathrm{~g}$. The fruits were washed in tap water, sterilized with $75 \%$ alcohol, then washed twice with sterile distilled water. The fruits were placed in a laminar air flow and dried under UV light for $10 \mathrm{~min}$. Following the drying process, the samples were punctured on the same side to a depth of $2 \mathrm{~mm}$ with a sterilized needle. Next, 20- $\mu \mathrm{L}$ C. gloeosporioides spore suspensions $\left(2 \times 10^{4}\right.$ conidia $)$ were prepared and contacted with the Ag particle and glass (control) samples for $15 \mathrm{~min}$. The wound and non-wound sites of the samples were then inoculated with $5-\mu \mathrm{L}$ spore suspensions $\left(5 \times 10^{3}\right.$ conidia). The fruits were placed in a sterilized plastic box $(40 \times 20 \times 45 \mathrm{~cm})$ with $100 \%$ relative humidity $(\mathrm{RH})$ and incubated at $28{ }^{\circ} \mathrm{C}$ for 7 days. Finally, the lesion lengths at each inoculation site were measured using an optical microscope.

\subsection{RT-PCR Analysis of Gene Expression}

The effect of the Ag particles on the melanin synthesis behavior of the C. gloeosporioides spores was evaluated by performing the RT-PCT analysis of five related genes, namely polyketide synthase (PKS), tetra-HN reductase scytalone (THR), scytalone dehydratase (SCD), exo-glucocanase (Ecg) and pectate lyase (PEL). Seven primers were designed for the RT-PCR analysis, and 18S rRNA was selected as the 
internal control [32]. The RNA of the spores contacted with the different Ag particles and glass (control) sample for 15 min were extracted using an RNA purification kit (BIO-GENESIS, Germany). cDNA synthesis was then performed using a commercial reverse transcription system (Magic RT Mastermix cDNA synthesis kit, BIO-GENESIS, Germany). Finally, the cDNA was used for real-time quantitative PCR tests with the following program: $95^{\circ} \mathrm{C}$ for $5 \mathrm{~min}$ (denaturation and hot start activation), 40 cycles of $95^{\circ} \mathrm{C}$ for $10 \mathrm{~s}$ and $60^{\circ} \mathrm{C}$ for $20 \mathrm{~s}$. After the real-time PCR, melting curves ( 65 to $99^{\circ} \mathrm{C}$ ) of the PCR products were analyzed.

\subsection{Morphology of C. Gloeosporioides Conidia}

To observe the effect of the Ag particles on the morphology of the C. gloeosporioides conidia, conidia samples $\left(10^{9}\right.$ conidia $\left./ \mathrm{mL}\right)$ were contacted with the Ag particles with a size of $1.2 \mu \mathrm{m}$ for $3 \mathrm{~h}$ then centrifuged at 13,300 rpm for $2 \mathrm{~min}$. The resulting pellets were washed with sterile water and pre-fixed with $2.5 \%$ glutaraldehyde for $2 \mathrm{~h}$. The pre-fixed cells were washed with phosphate buffered saline (PBS) two times and post-fixed with 1\% osmium tetroxide for $1 \mathrm{~h}$. After washing with PBS three times, a dehydration process was conducted with $30 \%, 50 \%, 70 \%, 80 \%, 90 \%$ and $100 \%$ of ethanol. Finally, the fixed cells were dried and gold-coated using an ion sputtering system (HITACHI HUS-SGB, Japan) and their morphology was observed by SEM (HITACHI S-3000N, Japan). Three replications were performed for each sample. All data were statistically analyzed using analysis of variance (ANOVA) test. In addition, the means of the various samples were compared using a Tukey-HSD test $(p=0.05)$ and Fisher's Least Significant Difference (LSD) test $(p=0.01)$. All of the analyses were performed using commercial statistical software (SPSS V. 20, IBM).

\section{Results and Discussion}

Figure 1 presents SEM images of the synthesized Ag particles. The laser parameters used to obtain the three types of Ag nanoparticles were $3 \mathrm{~W}-50 \mathrm{~mm} / \mathrm{s}-10 \mathrm{~nm}, 8 \mathrm{~W}-25 \mathrm{~mm} / \mathrm{s}-50 \mathrm{~nm}$ and 12.5 $\mathrm{W}-150 \mathrm{~mm} / \mathrm{s}-50 \mathrm{~nm}$, respectively. It was seen that the particle size increased with an increasing $\mathrm{Ag}$ film thickness and increased laser repetition rate. The corresponding particle heights for Figure 2 are 76, 288 and $515 \mathrm{~nm}$, respectively.

Figure 3 shows the relationship between the scanning speed and the laser input energy for initial $\mathrm{Ag}$ film thicknesses of 10 and $50 \mathrm{~nm}$, respectively. As shown, both figures contained three distinct regions. In Region I, characterized by a low laser energy and high scanning speed, the energy was insufficient to prompt dewetting of the Ag film. As the scanning speed and laser energy increased, the input energy also increased and hence dewetting occurred, resulting in the formation of Ag particles (Region II). However, at excessive laser energies and low scanning speeds (Region III), the input energy led to the ablation of the Ag film rather than dewetting, and, consequently, no particles were formed. In general, the results confirm that the dewetting process is strongly dependent on the laser power and scanning speed. In particular, for a given scanning speed, a high laser energy results in the ablation of the Ag film, while a low laser energy results in an Ag film with many isolated island structures. For a constant laser energy, the particles tend to become larger with increasing scanning speeds due to corresponding reductions in the thermal energy accumulation. It is noted that this finding is consistent with those reported in previous studies [33,34]. The results presented in Figure 3 confirm that the size of the particles produced in the dewetting process also depend on the thickness of the original Ag film. For a thicker film, the dewetting process can be performed at a higher energy, and particles with a micrometer scale are produced at all the corresponding scanning speeds. For a thinner film, particles can be obtained at a lower energy, and the particle size (nanometer) depends on the particular scanning speed applied [35]. Overall, the results show that the particle size decreases with an increasing laser energy and a decreasing film thickness. 


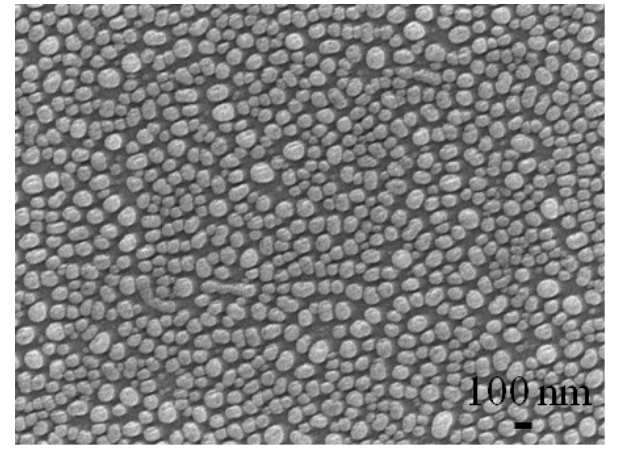

(a)

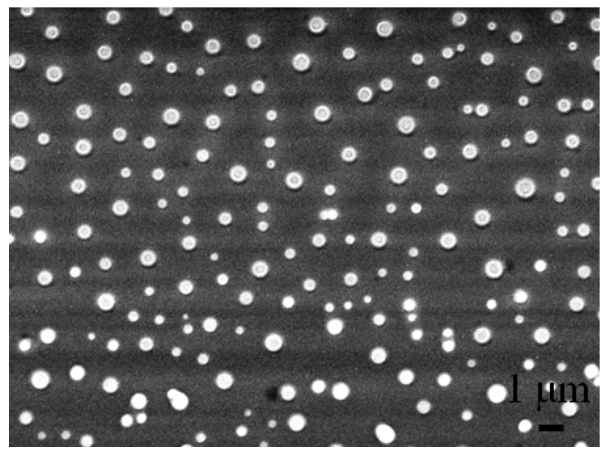

(b)

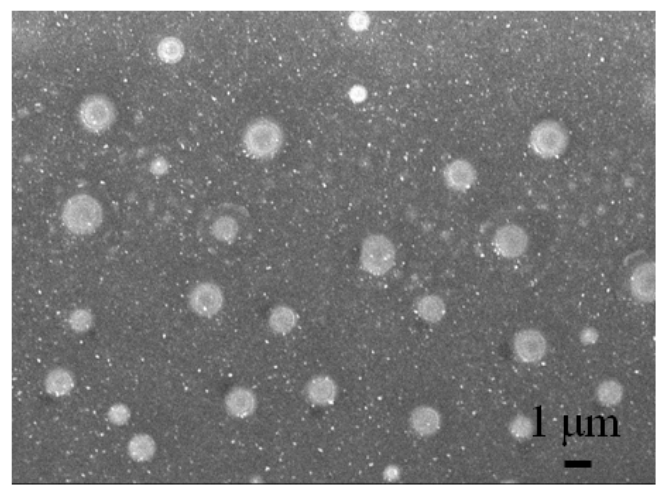

(c)

Figure 1. SEM images of Ag particles with a sizes of (a) $92 \mathrm{~nm}$, (b) $570 \mathrm{~nm}$ and (c) $1.2 \mu \mathrm{m}$.

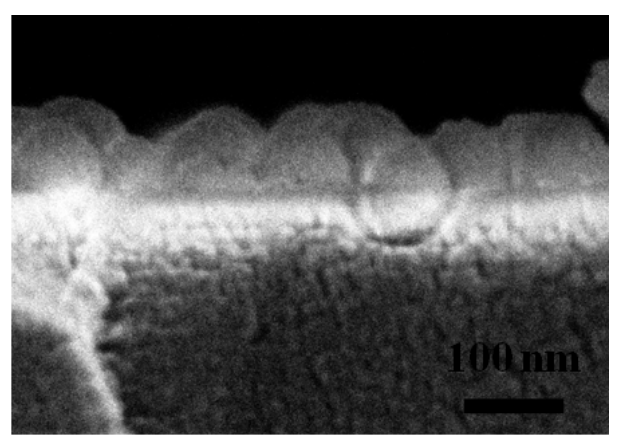

(a)

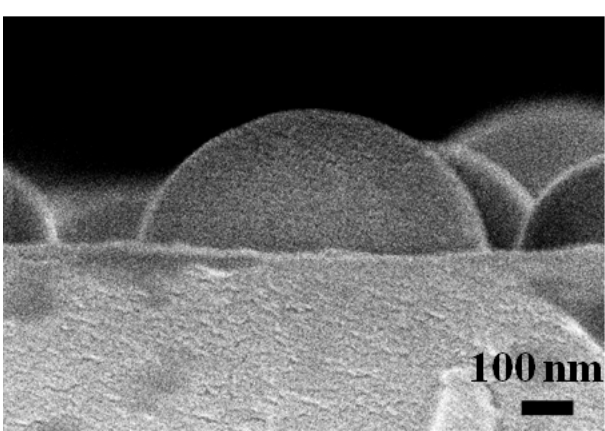

(b)

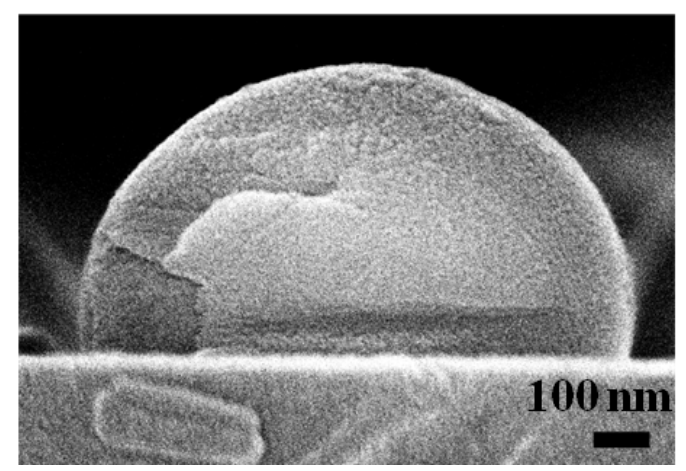

(c)

Figure 2. Cross-sectional images of Ag particles with different sizes of (a) $92 \mathrm{~nm}$, (b) $570 \mathrm{~nm}$ and (c) $1.2 \mu \mathrm{m}$. 


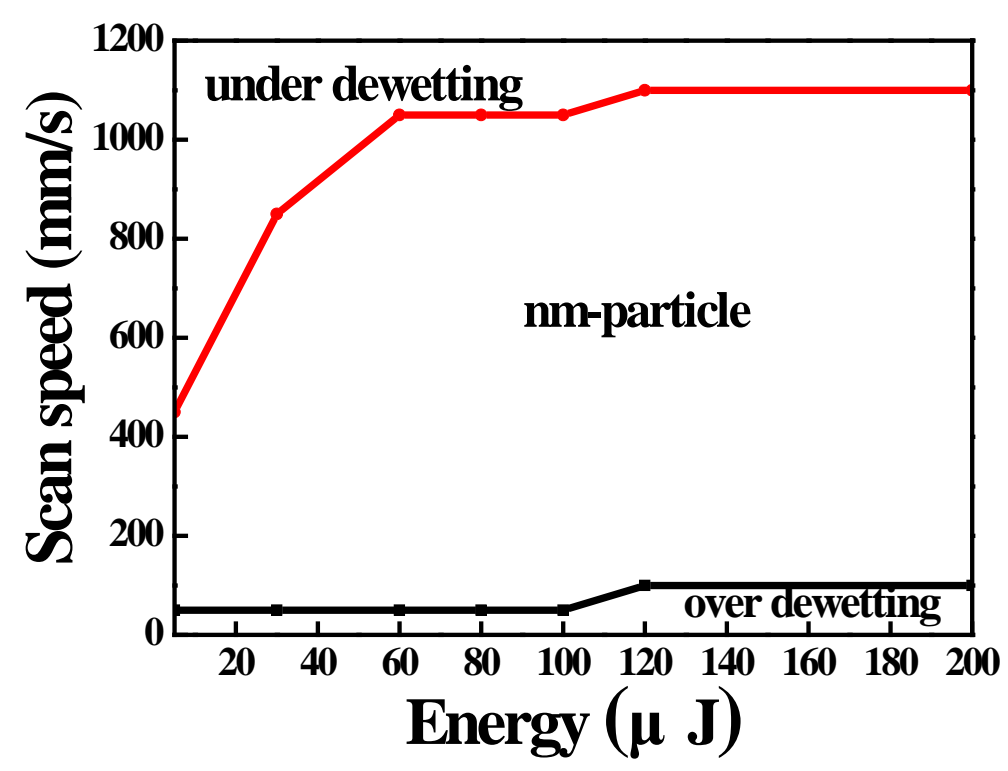

(a)

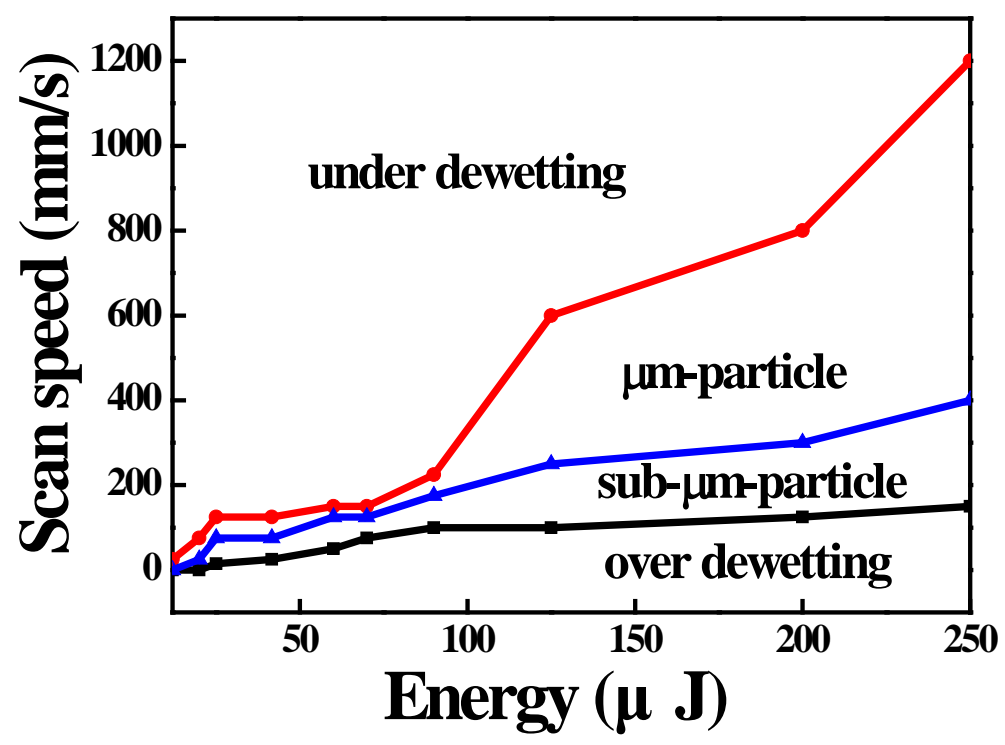

(b)

Figure 3. Relationship between scanning speed and laser input energy for initial Ag film thicknesses of (a) $10 \mathrm{~nm}$ and (b) $50 \mathrm{~nm}$.

Table 1 shows the surface roughness ( $\mathrm{Ra}$ ) and contact angle measurements of the various Ag samples. The surface roughness increased with increasing particle sizes as a result of the greater particle height (see Figure 2). The contact angle also increased with increasing particle sizes. For example, the particles with a size of $92 \mathrm{~nm}$ and $1.2 \mu \mathrm{m}$ had contact angles of $43^{\circ}$ and $73^{\circ}$, respectively. Surface roughness is another factor that affected biological activities, suggesting that microbes have difficulty attaching and moving on an ultra-smooth surface [14]. Figure 4 presents OM images showing the conidia growth of the $C$. gloeosporioides spores contacted with the different samples. In general, the results show that the treated samples $(92 \mathrm{~nm}, 570 \mathrm{~nm}$ and $1.2 \mu \mathrm{m})$ had significantly higher fungistatic properties than the control (glass) sample. The Ag sample with the largest particle size $(1.2 \mu \mathrm{m})$ achieved $100 \%$ fungistatics within a contact time of 5 min. For the sample with an Ag particle size of 570 
$\mathrm{nm}, 100 \%$ fungistatics was also achieved; however, the contact time increased to $10 \mathrm{~min}$. For the smallest particle size of $92 \mathrm{~nm}$, the sample contained 22 colonies after $15 \mathrm{~min}$. In other words, full fungistatics was not achieved. However, overall, the results confirm that the conidia growth suppression ability of all the samples increased with increasing particle sizes and contact times. The present results are consistent with those of [36-38], which showed that metallic Ag has an excellent inhibitory ability against both bacteria (Escherichia coli, Staphylococcus aureus and Pseudomonas aeruginosa) and fungi (Fusarium oxysporum and Botrytis cinerea).

Table 1. Roughness and contact angle measurements of different Ag particle samples.

\begin{tabular}{cccc}
\hline Sample Particle Size & Film Thickness $(\mathbf{n m})$ & Roughness $(\mathbf{n m})$ & Contact Angle $\left(^{\circ}\right)$ \\
\hline Glass & - & 0.3 & $63 \pm 2$ \\
$92 \mathrm{~nm}$ & 10 & $5 \pm 2$ & $43 \pm 2$ \\
$570 \mathrm{~nm}$ & 50 & $44 \pm 1$ & $51 \pm 2$ \\
$1.2 \mu \mathrm{m}$ & 50 & $73 \pm 3$ & $73 \pm 1$ \\
\hline
\end{tabular}

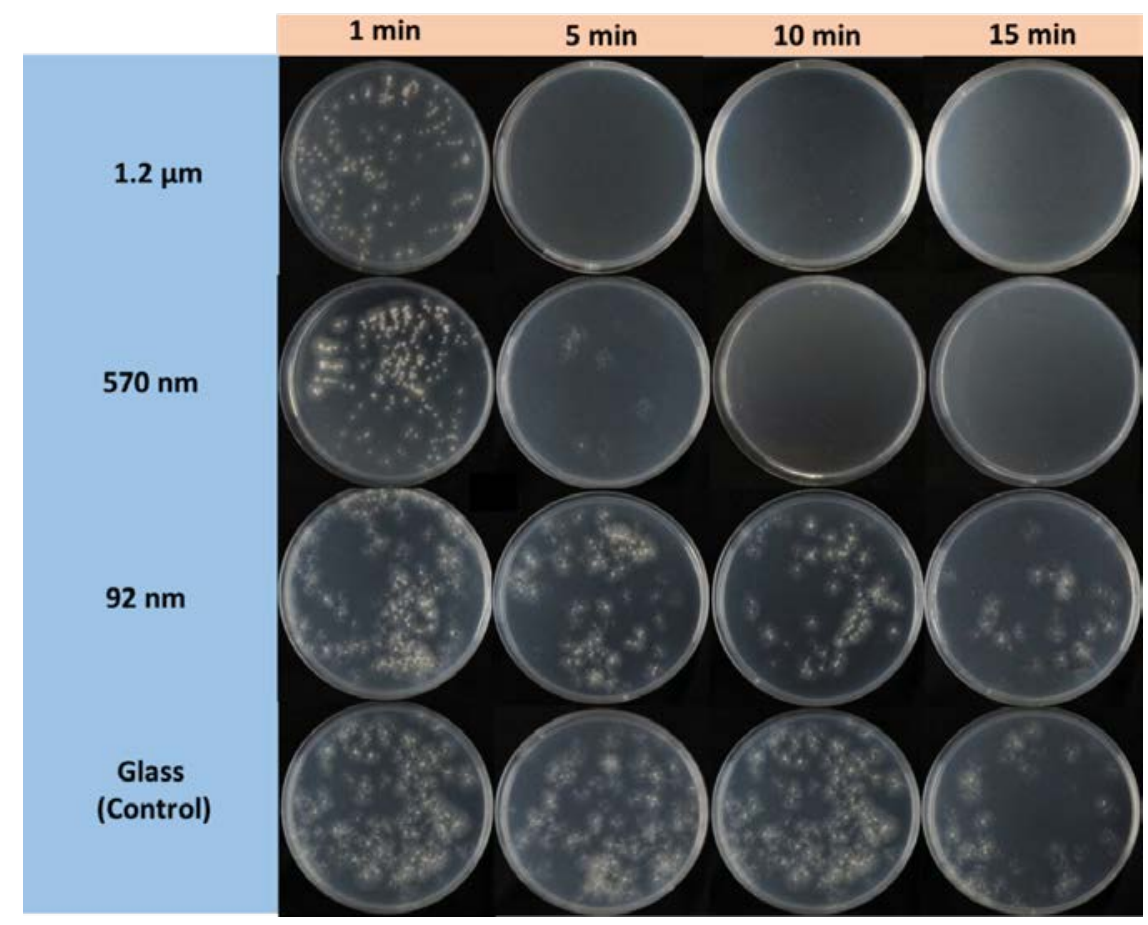

Figure 4. Conidia growth of C. gloeosporioides for different Ag particle sizes and contact times.

Figure 5 shows the spore germination rates of the $C$. gloeosporioides contacted with the different $\mathrm{Ag}$ samples for periods of 1 and $15 \mathrm{~min}$, respectively. For both contact periods, the spore germination rates of the treated samples were significantly lower than those of the untreated sample. Furthermore, for the Ag samples, the germination rates decrease by around $20 \%$ as the contact time was increased from 1 to $15 \mathrm{~min}$. The germination rates also decreased with increasing particle size. For example, given a contact time of $15 \mathrm{~min}$, the germination rate reduced from around $29 \%$ to $15 \%$ as the particle size increases from $92 \mathrm{~nm}$ to $1.2 \mu \mathrm{m}$. It is noted that this trend is consistent with the plate test results (see Figure 4). Anthracnose appressorium formation is one of the most important structures invading a host [32]. Figure 6 presents OM images showing the appressorium formation of $C$. gloeosporioides spores contacted with the treated and untreated samples. For the untreated sample, germination was observed after $2 \mathrm{~h}$ of cultivation, and the appressorium formation rate was equal to $40.2 \% \pm 6.2 \%$ after $8 \mathrm{~h}$. In addition, germ tube and appressorium formation were observed after 4 and $6 \mathrm{~h}$, respectively. However, for the treated samples, germ tube formation was not observed until $6 \mathrm{~h}$ of incubation. 
In addition, no appressorium formation was observed for any of the samples, even after $8 \mathrm{~h}$. In other words, the results confirm the ability of the Ag particles to inhibit the formation of Anthracnose.
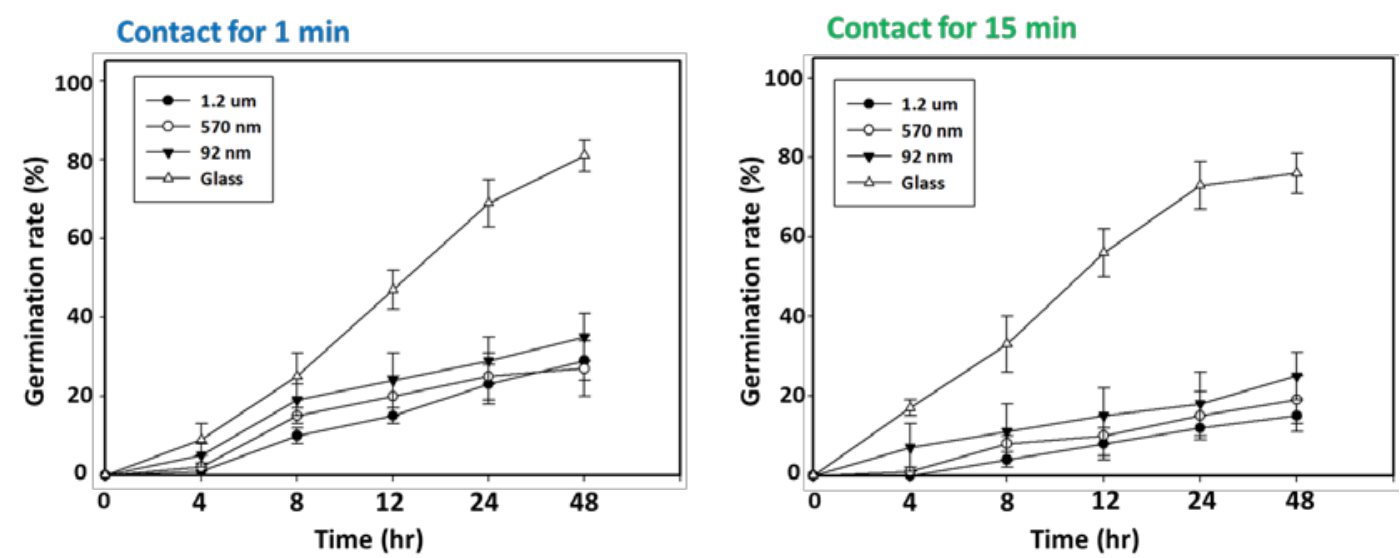

Figure 5. Spore germination rate of $C$. gloeosporioides for different Ag particle sizes and contact times.

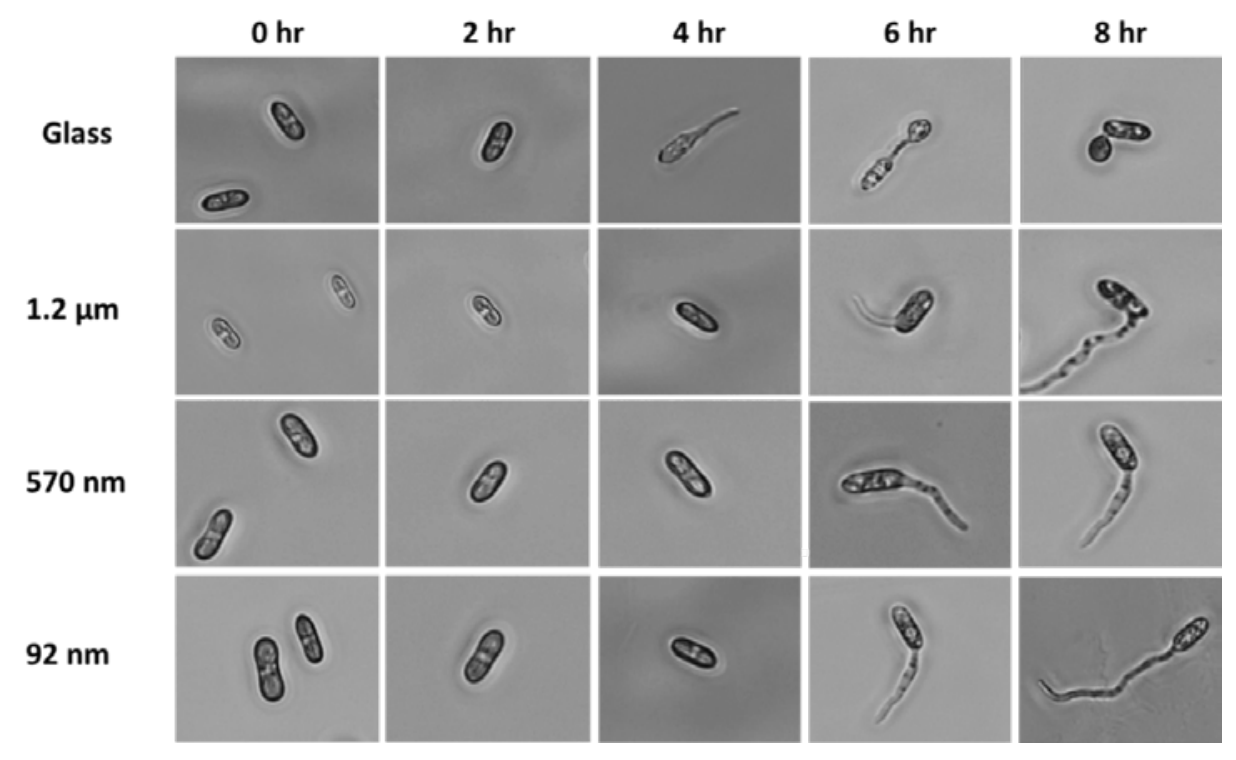

Figure 6. Formation of C. gloeosporioides for different Ag particle sizes and contact times.

Figure 7 shows the morphologies of the C. gloeosporioides spores treated with different Ag particles for 15 min then incubated in PDA at $28{ }^{\circ} \mathrm{C}$ for 6 days. Note that for each sample, the left and right images present front and rear views of the colony morphology, respectively. It can be observed that the melanin precipitation in the treated samples was greatly reduced compared to that in the untreated (control) sample. Among the treated samples, the sample with a 1.2- $\mu \mathrm{m}$ particle size had a particularly low melanin precipitation. Wei [32] showed that Anthracnose produce melanin to accumulate the swell pressure inside the press. In other words, the amount of melanin is one of the key factors determining the pathogenic ability of Anthracnose. Overall, the results presented in Figure 7 suggest that Ag particle treatment is effective at suppressing melanin expression and hence in limiting the activity of Anthracnose. Figure 8 shows the relative expressions of the laccase gene (LAC1), PKS, THR, SCD, Ecg and PEL genes following contact with the treated and un-treated samples. The results confirm that exposure to Ag particles resulted in a significant reduction in melanin synthesis compared to that for the untreated sample. Moreover, for each gene, the melanin synthesis reduced with an increasing particle size. 

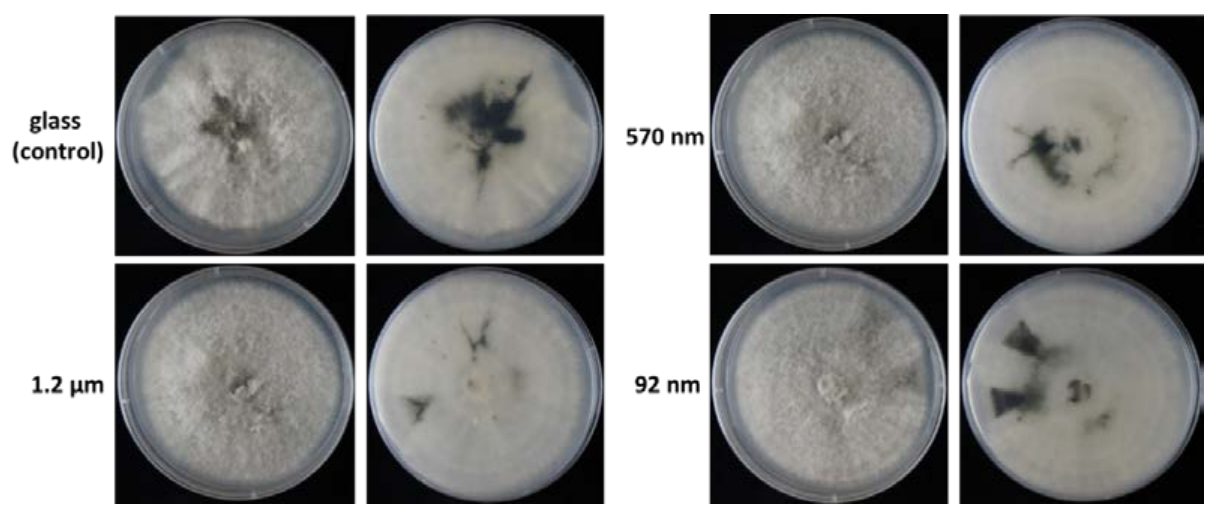

Figure 7. Morphologies of C. gloeosporioides following treatment with different Ag samples.

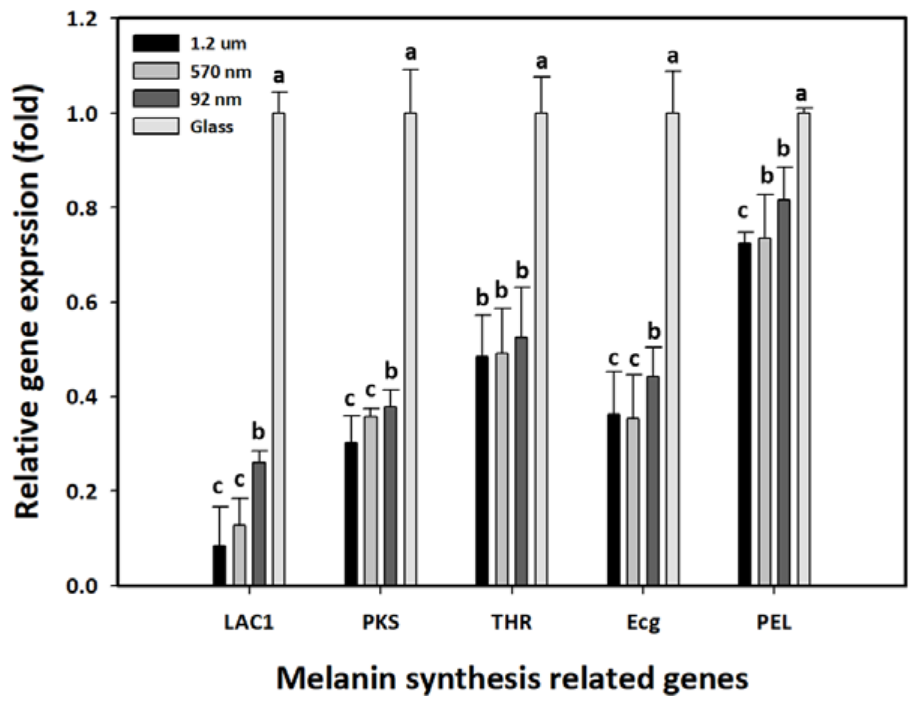

Figure 8. Relative expression of LAC1, PKS, THR, SCD, Ecg and PEL genes following treatment with different Ag samples. SR: internal reference 18 s rRNA; LAC1: laccase gene; PKS: polyketide synthase gene; THR: tetra-HN reductase scytalone gene; SCD: scytalone dehydratase gene; Ecg: exo-glucocanase gene; and PEL: pectate lyase gene.

Figure 9 shows the effect of the Ag nanoparticles on the extent of the anthracnose of the mango samples. Compared to the control sample, the pathogenicity of the C. gloeosporioides conidia was notably reduced in the treated samples. The detailed inoculation results presented in Table 2 show that the lesion size reduced from 13.50 to $11.00 \mathrm{~nm}$ as the Ag particle size increased from $92 \mathrm{~nm}$ to $1.2 \mu \mathrm{m}$. In other words, the results are consistent with those of the plate fungistatic and spore germination tests, which showed that the Ag sample with a particle size of $1.2 \mu \mathrm{m}$ had particularly good fungistatic properties and a superior suppression ability of C. gloeosporioides.

Table 2. Efficacy of different Ag particle samples for anthracnose treatment of mango.

\begin{tabular}{ccc}
\hline \multirow{2}{*}{ Treatment } & \multicolumn{2}{c}{ Lesion Size (mm) } \\
\cline { 2 - 3 } & Wound Made & Non-Wound Made \\
\hline Control (Glass) & $15.56 \pm 0.76^{\mathrm{a}}$ & $13.10 \pm 0.91^{\mathrm{a}}$ \\
$92 \mathrm{~nm}$ & $13.50 \pm 0.66^{\mathrm{b}}$ & $7.00 \pm 1.95^{\mathrm{b}}$ \\
$570 \mathrm{~nm}$ & $11.75 \pm 0.69^{\mathrm{c}}$ & $6.80 \pm 1.42^{\mathrm{b}}$ \\
$1.2 \mu \mathrm{m}$ & $11.00 \pm 0.66^{\mathrm{c}}$ & $3.30 \pm 1.15^{\mathrm{c}}$ \\
\hline
\end{tabular}

* significant differences at $p=0.05$ (ANOVA, post-hoc Tukey-HSD test). 

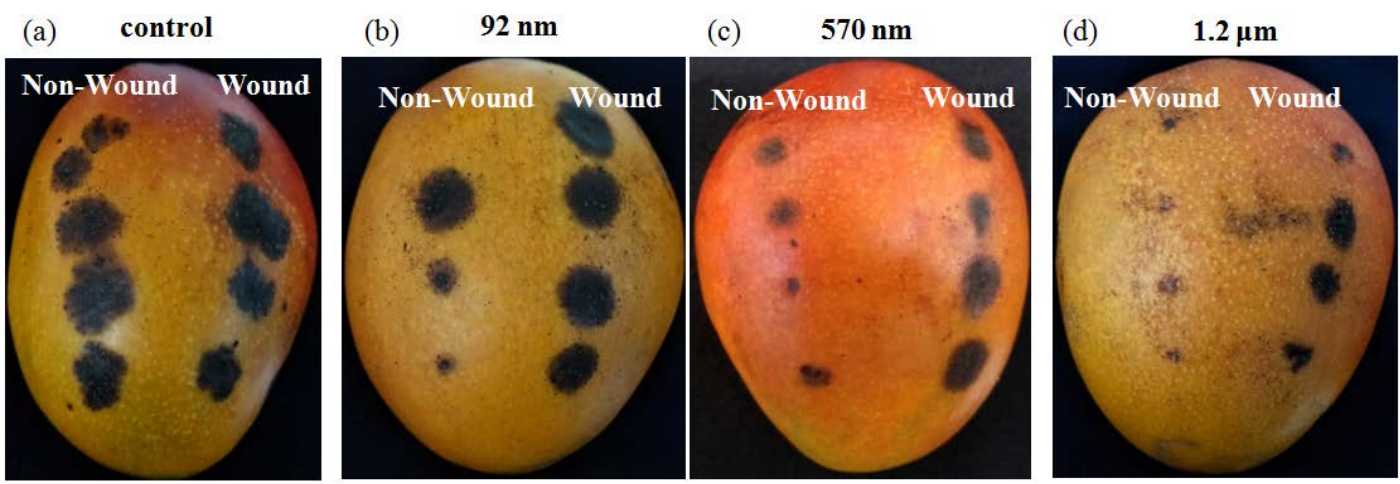

Figure 9. Effects of Ag particle size on anthracnose of mango: (a) control, (b) $92 \mathrm{~nm}$, (c) $570 \mathrm{~nm}$ and (d) $1.2 \mu \mathrm{m}$.

Figure 10 presents SEM images showing the morphologies of the C. gloeosporioides conidia following contact with the untreated control sample and the sample with an Ag particle size of $1.2 \mu \mathrm{m}$. The $C$. gloeosporioides conidia of the untreated sample had an oval cell-like appearance with a smooth surface. By contrast, the conidia surfaces for the treated sample contained small irregular fragments, indicating that exposure to the Ag particles resulted in damage to the cell surface and hence inhibited the invasion and growth of the C. gloeosporioides spores during incubation.

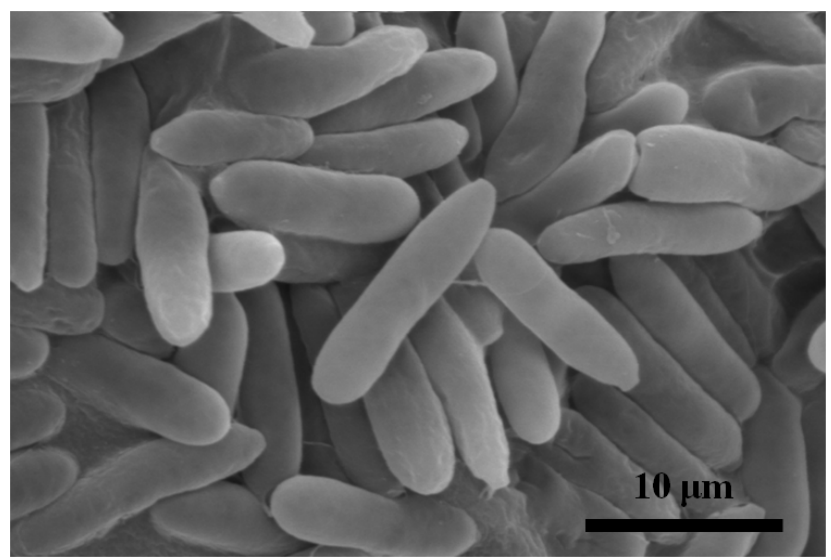

(a)

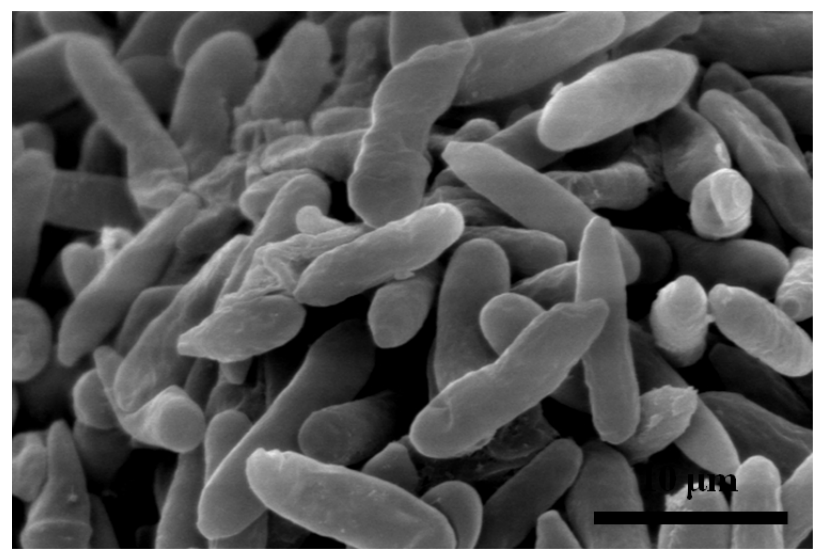

(b)

Figure 10. SEM micrographs of C. gloeosporioides treated with different Ag particle samples: (a) glass (control) and (b) $1.2 \mu \mathrm{m}$. 


\section{Conclusions}

Silver particles were prepared on glass slides using a combined thermal evaporation and laser dewetting process. It has been shown that the size of the particles can be controlled in the range of $92 \mathrm{~nm} \sim 1.2 \mu \mathrm{m}$ by adjusting the thickness of the Ag film deposited on the glass slide and the laser energy applied during the dewetting process. The antifungal performance of the Ag samples has been investigated by examining the conidia growth of $C$. gloeosporioides, a fungus spore associated with the anthracnose disease of mango. The results show that the conidia growth suppression effect increased with increasing Ag particle sizes and contact times. For the largest particle size of $1.2 \mu \mathrm{m}, 100 \%$ fungistatics was achieved within a contact time of $5 \mathrm{~min}$. Furthermore, even for the smallest particle size (92 nm), a strong antifungal performance was observed after a contact time of 15 min. A similar size-dependent effect was also observed in the spore germination and pathogenicity tests. Overall, the present results confirm that Ag particles have an excellent inhibitory ability on C. gloeosporioides.

Author Contributions: Y.-H.L. conceived of the study, and participated in its design and coordination. J.-J.W. and Y.-T.W. carried out the methodology and formal analysis. Y.-J.L. did some antifungistic experiments and data curation. H.-K.L. participated in the design of the thin film and helped to draft the manuscript. All authors discussed the results and commented on the manuscript.

Funding: The APC was funded by the Ministry of Science and Technology of Taiwan under Grants No. MOST 108-2221-E-110-001.

Acknowledgments: The authors gratefully acknowledge the financial support provided to this study by the Ministry of Science and Technology of Taiwan under Grants No. MOST 106-2221-E-020-008.

Conflicts of Interest: The authors declare no conflict of interest.

\section{References}

1. Khalid Akhtar, P.; Alam, S.S. Assessment keys for some important diseases of mango. Pak. J. Biol. Sci. 2002, 5, 246-250.

2. Tucho, A.; Lemessa, F.; Berecha, G. Distribution and occurrence of mango anthracnose (colletotrichum gloesporioides penz and sacc) in humid agro-ecology of southwest ethiopia. Plant Pathol. J. 2014, 13, $268-277$. [CrossRef]

3. He, L.; Liu, Y.; Mustapha, A.; Lin, M. Antifungal activity of zinc oxide nanoparticles against Botrytis cinerea and Penicillium expansum. Microbiol. Res. 2011, 166, 207-215. [CrossRef] [PubMed]

4. Villapún, V.; Dover, L.; Cross, A.; González, S. Antibacterial Metallic Touch Surfaces. Materials 2016, 9, 736. [CrossRef] [PubMed]

5. Huang, C.H.; Huang, Y.S.; Lin, Y.S.; Lin, C.H.; Huang, J.C.; Chen, C.H.; Li, J.B.; Chen, Y.H.; Jang, J.S.C. Electrochemical and biocompatibility response of newly developed TiZr-based metallic glasses. Mater. Sci. Eng. C 2014, 43, 343-349. [CrossRef]

6. Mahdizadeh, V.; Safaie, N.; Khelghatibana, F. Evaluation of antifungal activity of silver nanoparticles against some phytopathogenic fungi and Trichoderma harzianum. J. Crop Prot. 2015, 4, 291-300.

7. Herman, A.; Herman, A.P. Nanoparticles as Antimicrobial Agents: Their Toxicity and Mechanisms of Action. J. Nanosci. Nanotechnol. 2014, 14, 946-957. [CrossRef]

8. Soo-Hwan, K.; Hyeong-Seon, L.; Deok-Seon, R.; Soo-Jae, C.; Lee, D.-S. Antibacterial Activity of Silver-nanoparticles Against Staphylococcus aureus and Escherichia coli. Korean J. Microbiol. Biotechnol. 2011, 39, 77-85.

9. Nie, C.; Yang, Y.; Cheng, C.; Ma, L.; Deng, J.; Wang, L.; Zhao, C. Bioinspired and biocompatible carbon nanotube-Ag nanohybrid coatings for robust antibacterial applications. Acta Biomater. 2017, 51, 479-494. [CrossRef]

10. Chowdappa, P.; Gowda, S.; Chethana, S.C.; Madhura, S. Antifungal activity of chitosan-silver nanoparticle composite against Colletotrichum gloeosporioides associated with mango anthracnose. Afr. J. Microbiol. Res. 2014, 8, 1803-1812. [CrossRef]

11. Chernousova, S.; Epple, M. Silver as antibacterial agent: Ion, nanoparticle, and metal. Angew. Chem. 2013, 52, 1636-1653. [CrossRef] [PubMed] 
12. Chu, J.P.; Jang, J.S.C.; Huang, J.C.; Chou, H.S.; Yang, Y.; Ye, J.C.; Wang, Y.C.; Lee, J.W.; Liu, F.X.; Liaw, P.K.; et al. Thin film metallic glasses: Unique properties and potential applications. Thin Solid Film. 2012, 520, 5097-5122. [CrossRef]

13. Huang, J.C.; Chu, J.P.; Jang, J.S.C. Recent progress in metallic glasses in Taiwan. Intermetallics 2009, 17, 973-987. [CrossRef]

14. Chen, H.-W.; Hsu, K.-C.; Chan, Y.-C.; Duh, J.-G.; Lee, J.-W.; Jang, J.S.-C.; Chen, G.-J. Antimicrobial properties of $\mathrm{Zr}-\mathrm{Cu}-\mathrm{Al}-\mathrm{Ag}$ thin film metallic glass. Thin Solid Film. 2014, 561, 98-101. [CrossRef]

15. Kanhed, P.; Birla, S.; Gaikwad, S.; Gade, A.; Seabra, A.B.; Rubilar, O.; Duran, N.; Rai, M. In vitro antifungal efficacy of copper nanoparticles against selected crop pathogenic fungi. Mater. Lett. 2014, 115, 13-17. [CrossRef]

16. Janbua, W.; Bongkarn, T.; Vittayakorn, W.; Vittayakorn, N. Direct synthesis and growth mechanism of metal molybdate ( $\mathrm{AMoO} 4 ; \mathrm{A}=\mathrm{Ca}$ and $\mathrm{Ba}$ ) fine particles via the mechanochemical method. Ceram. Int. 2017, 43, S435-S443. [CrossRef]

17. Velgosová, O.; Mražíková, A.; Marcinčáková, R. Influence of pH on green synthesis of Ag nanoparticles. Mater. Lett. 2016, 180, 336-339. [CrossRef]

18. Kumar, N.; Alam, F.; Dutta, V. Deposition of Ag and Au-Ag alloy nanoparticle films by spray pyrolysis technique with tuned plasmonic properties. J. Alloy. Compd. 2014, 585, 312-317. [CrossRef]

19. Raffi, M.; Akhter, J.I.; Hasan, M.M. Effect of annealing temperature on Ag nano-composite synthesized by sol-gel. Mater. Chem. Phys. 2006, 99, 405-409. [CrossRef]

20. Bradley, J.-C.; Babu, S.; Carroll, B.; Mittal, A. A study of spatially coupled bipolar electrochemistry on the sub-micrometer scale: Colloidal particles on surfaces and cylinders in nuclear-track etched membranes. J. Electroanal. Chem. 2002, 522, 75-85. [CrossRef]

21. Oh, Y.; Lee, M. Single-pulse transformation of Ag thin film into nanoparticles via laser-induced dewetting. Appl. Surf. Sci. 2017, 399, 555-564. [CrossRef]

22. Kumar, K.; Swaminathan, P. Role of silver nanoparticles in the dewetting behavior of copper thin films. Thin Solid Film. 2017, 642, 364-369. [CrossRef]

23. Datta, D.P.; Chettah, A.; Siva, V.; Kanjilal, D.; Sahoo, P.K. Dewetting induced Au-Ge composite nanodot evolution in SiO2. Appl. Surf. Sci. 2018, 428, 676-683. [CrossRef]

24. Oh, Y.; Lee, J.; Lee, M. Fabrication of Ag-Au bimetallic nanoparticles by laser-induced dewetting of bilayer films. Appl. Surf. Sci. 2018, 434, 1293-1299. [CrossRef]

25. Maurya, S.K.; Uto, Y.; Kashihara, K.; Yonekura, N.; Nakajima, T. Rapid formation of nanostructures in Au films using a CO 2 laser. Appl. Surf. Sci. 2018, 427, 961-965. [CrossRef]

26. Heinz, M.; Srabionyan, V.V.; Avakyan, L.A.; Bugaev, A.L.; Skidanenko, A.V.; Kaptelinin, S.Y.; Ihlemann, J.; Meinertz, J.; Patzig, C.; Dubiel, M.; et al. Formation of bimetallic gold-silver nanoparticles in glass by UV laser irradiation. J. Alloy. Compd. 2018, 767, 1253-1263. [CrossRef]

27. Kline, J.E.; Leonard, J.P. Suppression of dewetting phenomena during excimer laser melting of thin metal films on SiO2. Thin Solid Film. 2005, 488, 306-313. [CrossRef]

28. Makarov, S.V.; Milichko, V.A.; Mukhin, I.S.; Shishkin, I.I.; Zuev, D.A.; Mozharov, A.M.; Krasnok, A.E.; Belov, P.A. Controllable femtosecond laser-induced dewetting for plasmonic applications. Laser Photonics Rev. 2016, 10, 91-99. [CrossRef]

29. Busleev, N.I.; Ivanova, A.K.; Kudryashov, S.I.; Rudenko, A.A.; Zayarny, D.A.; Ionin, A.A. Fano Resonances as Optical Markers of Sub-Wavelength Nanoparticle Packaging and Elemental Segregation in Laser-Dewetted Au-Pd Film. Plasmonics 2019, 14, 2013-2019. [CrossRef]

30. Nastulyavichus, A.A.; Smirnov, N.A.; Kudryashov, S.I.; Ionin, A.A.; Saraeva, I.N.; Busleev, N.I.; Rudenko, A.A.; Khmel'nitskii, R.A.; Zayarnyi, D.A. Formation of nanoparticles from thin silver films irradiated by laser pulses in air. Quantum Electron. 2018, 48, 251-254. [CrossRef]

31. Benware, B.R.; Macchietto, C.D.; Moreno, C.H.; Rocca, J.J. Demonstration of a high average power tabletop soft X-Ray Laser. Phys. Rev. Lett. 1998, 81, 5804-5807. [CrossRef]

32. Wei, Y.; Pu, J.; Zhang, H.; Liu, Y.; Zhou, F.; Zhang, K.; Liu, X. The laccase gene (LAC1) is essential for Colletotrichum gloeosporioides development and virulence on mango leaves and fruits. Physiol. Mol. Plant Pathol. 2017, 99, 55-64. [CrossRef]

33. Leroy, F.; Borowik, Ł.; Cheynis, F.; Almadori, Y.; Curiotto, S.; Trautmann, M.; Barbé, J.C.; Müller, P. How to control solid state dewetting: A short review. Surf. Sci. Rep. 2016, 71, 391-409. [CrossRef] 
34. Gazit, N.; Klinger, L.; Rabkin, E. Chemically-induced solid-state dewetting of thin Au films. Acta Mater. 2017, 129, 300-311. [CrossRef]

35. Lo Savio, R.; Repetto, L.; Guida, P.; Angeli, E.; Firpo, G.; Volpe, A.; Ierardi, V.; Valbusa, U. Control of the micrometric scale morphology of silicon nanowires through ion irradiation-induced metal dewetting. Solid State Commun. 2016, 240, 41-45. [CrossRef]

36. Ouda, S.M. Antifungal activity of sliver and copper nanoparticles on two plant pathogens, Alternaria alternata and Botrytis cinerea. Res. J. Microbiol. 2014, 9, 34-42. [CrossRef]

37. Chu, Y.Y.; Lin, Y.S.; Chang, C.M.; Liu, J.K.; Chen, C.H.; Huang, J.C. Promising antimicrobial capability of thin film metallic glasses. Mater. Sci. Eng. CMater. Biol. Appl. 2014, 36, 221-225. [CrossRef]

38. Ashajyothi, C.; Prabhurajeshwar, C.; Handral, H.K.; Kelmani, R.C. Investigation of antifungal and anti-mycelium activities using biogenic nanoparticles: An eco-friendly approach. Environ. Nanotechnol. Monit. Manag. 2016, 5, 81-87. [CrossRef]

(C) 2020 by the authors. Licensee MDPI, Basel, Switzerland. This article is an open access article distributed under the terms and conditions of the Creative Commons Attribution (CC BY) license (http://creativecommons.org/licenses/by/4.0/). 